the possibility of interchange and gives appropriate table headings in his Sea and Air Navigation Tables, 1938. Full advantage of the reversal cannot be taken when the PZS triangle is divided by perpendiculars from $\mathrm{Z}$ or $\mathrm{S}$; but some benefit appears possible.

I give no numerical examples since these cannot be fully illustrated. However the maximum discrepancy in altitude, before interpolation for declination, in the examples I have done using Aquino's 1938 tables (at an interval of $1^{\circ}$ in $h_{1}$ and $h_{2}$ ) is $0: 2$.

Before writing such a note as this, an author has a duty to examine published material and to refer to relevant work; in this case it is a formidable task and I cannot believe that such references do not exist. I await with interest their revelation; in anticipation I quote one of the many manuscript annotations made by Admiral Radler de Aquino in my valued copy of his 1938 tables: he writes (in connection with a minor acknowledgment) 'This is the first time I mention this : Errare humanum est.'

\title{
Automatic Radar Plotters: the Importance of the Future Position Control
}

$$
\text { Captain F. J. Wylie, O.B.E., R.N.(ret.) }
$$

ANYONE who has read articles by the present writer about automatic radar plotters but has not handled at sea one of those systems in which the vector lengths are time-correlated and have a fine (minute-by-minute) adjustment, might think that they tend to exaggerate its importance as an aid to realistic and rapid appraisal. I hope that the pictorial presentation which follows may serve to reverse such opinions even though, with still pictures, it is difficult to create the sense of a continuous and rapid series of brief manual movements and mental assessments.

Far from needing elimination, as suggested by Riggs (Journal, 28, I 43), the rapidly extensible vectors lend apparent acceleration to the radar picture, which always changes so slowly on the PPI, and thus convey with verisimilitude a sense of the predicted movement of the entire complement of echoes in their proper mutual relationship. Further, in situations demanding particular care or perhaps a change of course or speed, they can be used to give a rapid forecast of the probable duration of the emergency.

In the seven figures which follow, the situation represented is one in which own ship (O) has two ships (A and B) crossing from starboard and one (D) crossing from port; a fourth ship (C) is overtaking from the starboard quarter. The caption on each figure is important. Figures I, 2 and 4 (true plot) and 3 (relative plot) represent the appraisal, although the pause after Fig. I is hardly necessary; evasive action is planned on 2, taken on 5 (true plot) and course resumed on 6 (true plot), with a final check on 7 (relative).

Of course the verbiage makes this sound complicated but it has to be remembered that changes of plot method are instantaneous while changes of vector length take only a second or two. The vector lengths chosen here are quite 
arbitrary; as minute-by-minute changes are available, the vector picture may be studied at any time ahead which suits the observer. As the process of extending a vector may be almost continuous, the appropriate future moment becomes obvious. In the figures equal time changes have been adopted to facilitate comparison; also course changes have been assumed to occur instantaneously. Each figure represents a study point; the captions show that four or five seconds have been allowed for study in some cases, rather less in others. Different periods will be needed depending on whether the intention is to consider action or to check an appraisal. It has been assumed of course that the observer has been looking at the radar picture for a while before starting the action described.

The intelligence which emerges at each successive study point will be:

Fig. I. Early danger from B; probable danger from $\mathrm{C}$ later; caution with $\mathrm{A}$ and $\mathrm{D}$, particularly if intending to alter course.

Fig. 2. Collision danger with $B$ at 25 min.

Fig. 3. Snap check on relative plot confirms 1 and 2 above and shows that $A$ and D will pass ahead on present courses.

Fig. 4. Confirms danger of colliding with $C$ at $48 \mathrm{~min}$. Shows that, unless they alter, ships A, B, C and D should have no problems with one another.

Action must be taken to avoid B, preferably a turn to starboard; further study of 24-min. vectors (Fig. 2) shows clearly that a turn to starboard of about $30^{\circ}$ will clear $\mathrm{B}$ by a good margin but one of up to $70^{\circ}$ would take $\mathrm{O}$ well ahead of $\mathrm{C}$ and would disclose our intentions more quickly to $B$ and $C$. It also shows that subsequent care of $\mathrm{C}$ will be necessary. Duration of manœuvre, minimum $18 \mathrm{~min}$.; better $24 \mathrm{~min}$. A return to any vector length for re-examination is, of course, virtually instantaneous.

Own ship decides to alter $60^{\circ}$ to starboard at $12 \mathrm{~min}$.; there should still be about $10 \mathrm{~min}$. to spare before starting the alteration.

Fig. 5. Situation at $12 \mathrm{~min}$., immediately after altering course. If vectors are reduced to $14 \mathrm{~min}$., it will be seen that $O$ should pass 2 miles ahead of $\mathrm{C}$ at about $26 \mathrm{~min}$. The $24-\mathrm{min}$. vector shows that it should be clear to resume course at $36 \mathrm{~min}$.

Fig. 6. Situation at $36 \mathrm{~min}$. immediately after resuming original course. 24-min. vector shows that $O$ will pass about $I \cdot 6$ miles astern of $D$ at about $5^{8} \mathrm{~min}$.

Fig. 7. Snap check on 6 ; relative plot shows $D$ will cross ahead of $O$ at about $50 \mathrm{~min}$., distance $1 \cdot 4$ miles, $C$ is at about $1 \cdot 8$ miles, opening.

Reading the article thus far will have taken about $3 \mathrm{~min}$. The total time for the situation to develop as described up to passing clear would be 50 to $60 \mathrm{~min}$., but the total time spent on switching, study and appraisal should not be more than 45 to 60 seconds, depending upon experience. Of course, the suitability of the manœuvres may be checked by the trial manœuvre facility, if available. 


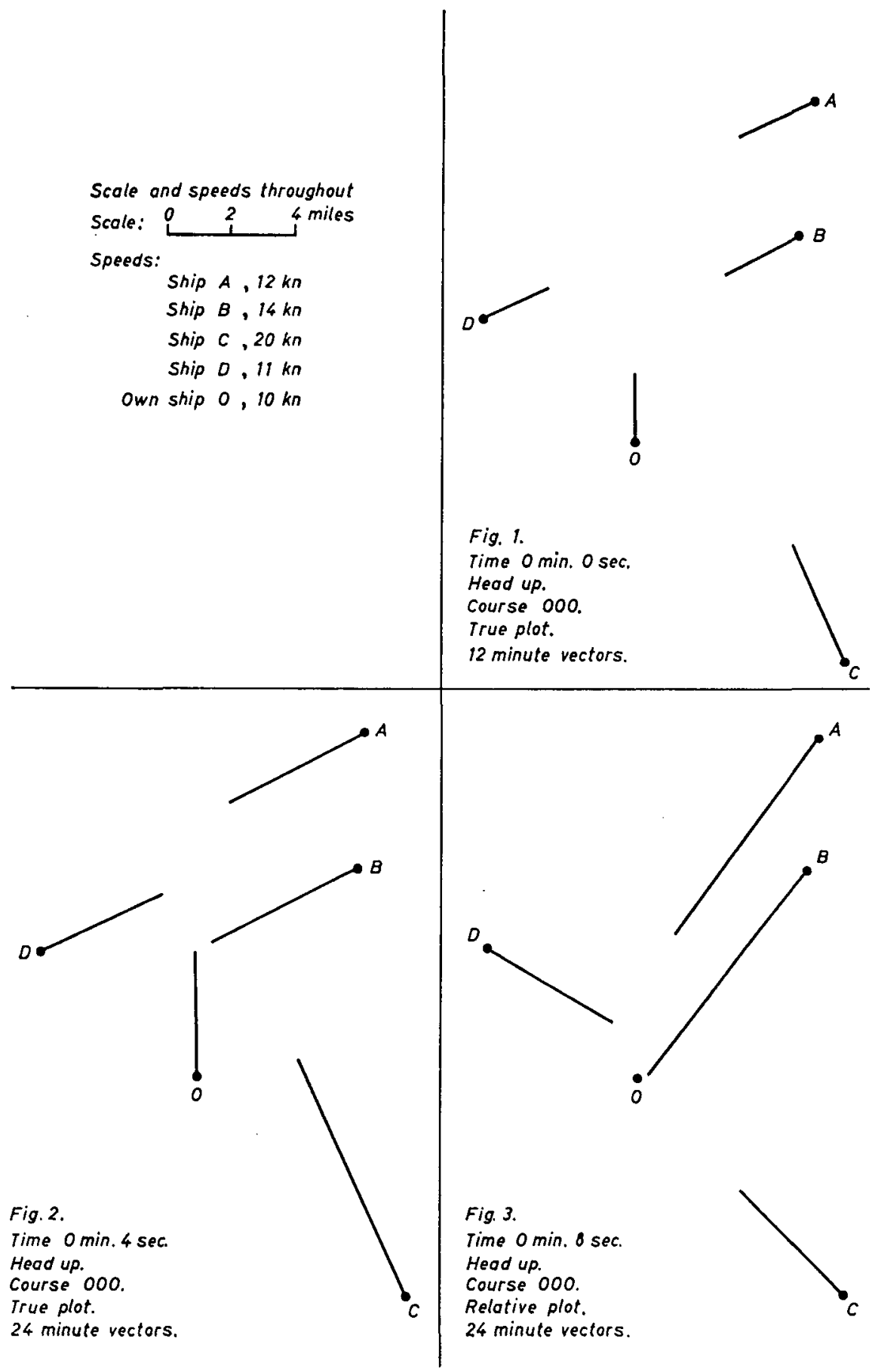




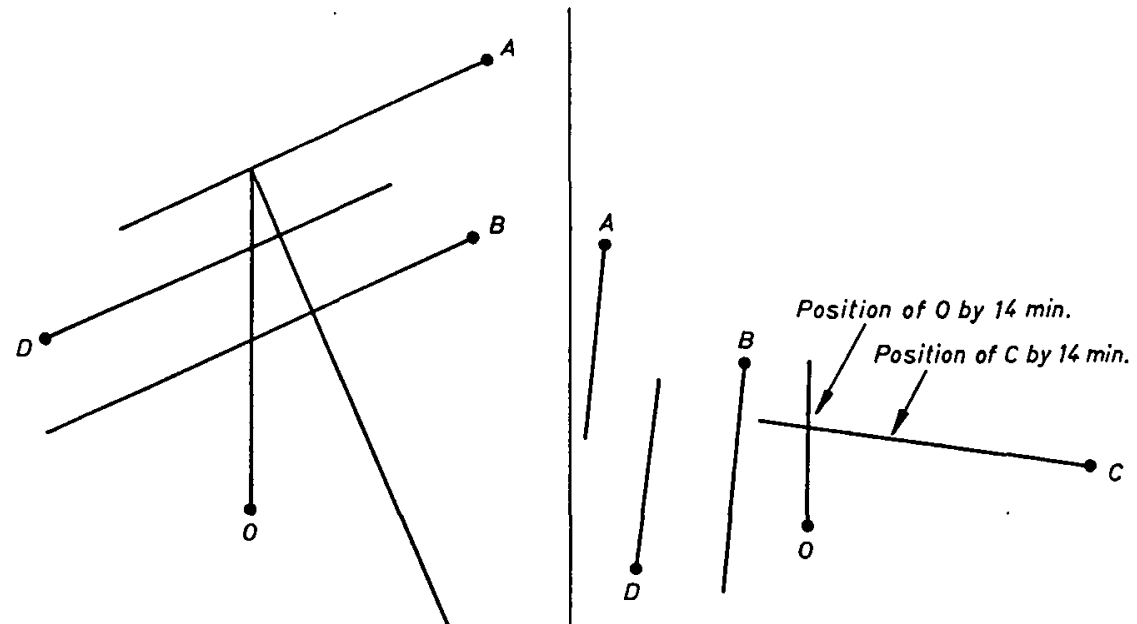

Fig. 4.

Time 0 min. 12 sec.

Head up.

Course 000.

Irue plot.

48 minute vectors.

Fig. 5.

Time $12 \mathrm{~min}$. 0 sec.

Head up.

Course 060.

true plot.

24 minute vectors.

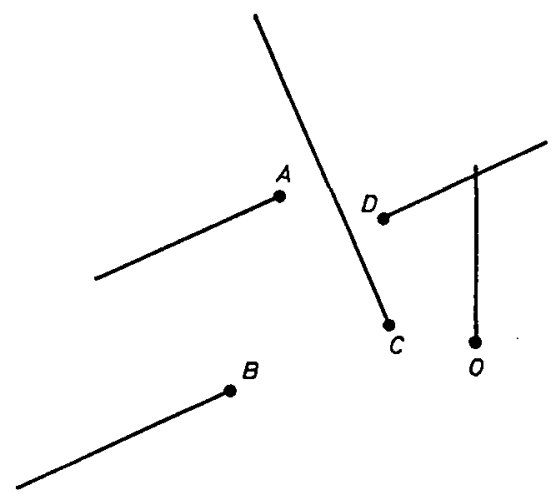

Fig. 6.

Time 36 min. 0 sec.

Head up.

Course 000.

True plot.

24 minute vectors.

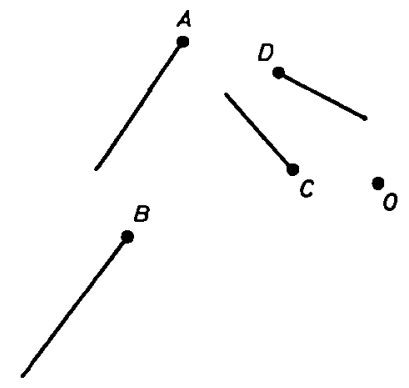

Fig. 7.

Time $36 \mathrm{~min} .6 \mathrm{sec}$.

Head up.

Course 000 .

Relative plot.

12 minute vectors. 